\title{
Marsi kanalite ajalugu
}

\section{$\underline{\text { Tõnu Tuvikene }}$}

Marss on oma heleduse ja silmatorkava punase värvusega juba aastatuhandeid inimeste tähelepanu köitnud, kuid mitte mingi muu nähtus pole Marsi puhul tekitanud nii palju eriarvamusi ja puhunud lõkkele kirgi kui Marsi kanalid. Just kanalite avastamine oli see, mille järel sai populaarseks hüpotees arukatest olenditest Marsil. On ju eesti keeleski olemas nende tähistamiseks eriline sõna "marslane".

Seejuures ühegi teise taevakeha asukate jaoks pole eri nimetust kasutusele võetud. (Puhtspekulatiivse arvamuse, et Marsil nagu ka teistel planeetidel võiks olla arukaid olendeid, ütles esimesena välja C. Huygens juba 17. sajandil.)

Kanalite ajalugu sai alguse 1877. aastal, kui neid järjekordse Marsi suure vastasseisu ajal märkas itaalia astronoom Giovanni Virginio Schiaparelli (1835 - 1910). Sama vastasseisu ajal avastas muuseas ameerika astronoom Asaph Hall

\section{Miks on Marssi raske vaadelda?}

Marsi pinna põhjalikum vaatlemine on võimalik vaid mõni kuu enne ja pärast vastasseisu, st kui meievaheline kaugus on väikseim. Vastasseisuks nimetatakse astronoomias olukorda, kui Päike, Maa ja mõni planeet (antud juhul Marss) on kõik ühel sirgel ning Maa ja planeet seejuures veel Päikesest ühel pool (vastupidisel juhul on Maa ja planeedi omavaheline kaugus suurim). Marsi vastasseisud toimuvad iga 2 aasta ja 50 päeva järel.

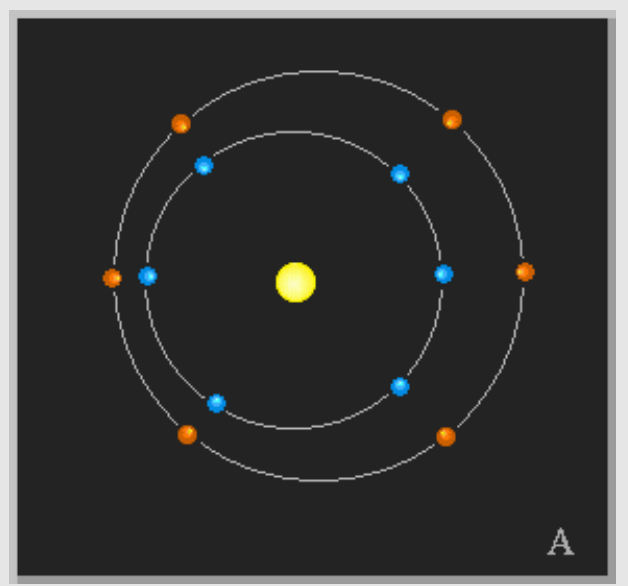
(1829 - 1907) Marsi kaaslased. Õigupoolest nimetas Schiaparelli nähtud joonekujulisi moodustisi itaaliakeelse sõnaga canali, mis tähendab ühtaegu nii (looduslikku) väina kui ka (kunstlikku) kanalit. Avastuse interpreteerimisel ja selle tõlkimisel teistesse keeltesse kasutati paraku just seda teist, paremat fantaasialendu võimaldavat tähendust. Schiaparelli ise pidas neid kindlalt looduslikeks, nimetades neid sageli koguni jõgedeks.

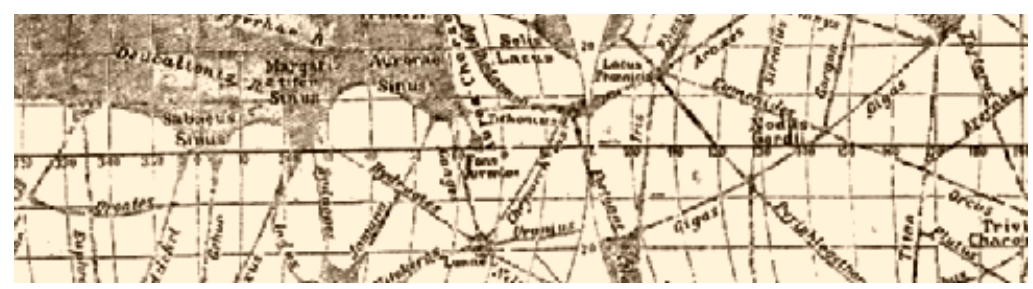

Schiaparelli koostatud Marsi kanalite kaart. Vaata seda ka suuremalt. 
Kuna Marsi orbiit on väga piklik, siis võivad tema kaugused Maast vastasseisu ajal erineda üksteisest ligi kaks korda, ulatudes 55,7 miljo-nist kilomeetrist kuni 101,2 miljoni kilomeetrini.

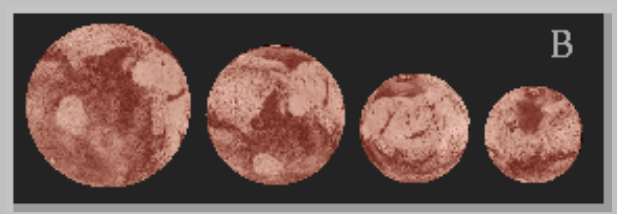

Kuna planeedi näiv läbimõõt ja pinnadetailide nähtavus sõltuvad kaugusest pöördvõrdeliselt, siis on arusaadav, miks Marsi-uurijate hulgas on eriti hinnatud nn suured vastasseisud. Nii nimetatakse vastasseise, mille ajal Marss on periheelis, st. oma lähimas punktis Päikesele, ja vastavalt on siis väikseim ka Maa ja Marsi vaheline kaugus. Suured vastasseisud toimuvad kas iga 15 või 17 aasta järel.

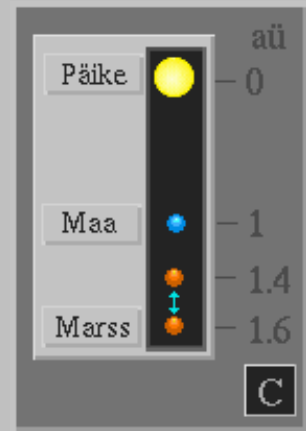

Eelmine oli 1988. aastal ja järgmine toimub 2003. aastal, kusjuures Marsi kaugus on siis kõige väiksem viimaste aastatuhandete jooksul. Kuid ka sellisel eriti soodsal juhul jääb Marss ikkagi umbes 150 korda kaugemale kui Kuu ja tema näiv läbimõõt 25 nurgasekundit jääb täiskuule alla üle 70 korra. Peale selle on Marsil erinevalt Kuust atmosfäär, mis vaatamata oma horredusele segab pisemate detailide vaatamist. Eriti halvaks läheb asi siis, kui Marsil hakkab möllama globaalne tolmutorm. Halvemal juhul pole siis mitu nädalat üldse Marsi pinda näha. Õnnetuseks kipuvad need toimuma just vastasseisude ajal. Põhivaenlaseks on Marsi nagu iga teisegi taevakeha vaatlemisel siiski Maa atmosfäär, mis tekitab kujutise värisemist. Detailide nägemiseks peab vaatleja ootama hetki, kui kujutis on sekundi murdosa jooksul stabiilne, ja siis nähtu mälu järgi üles joonistama. Fotodelt pole planeetide peenemaid detaile üldse näha, sest pildistamiseks vajaliku aja jooksul "määrib" atmosfäär kujutise laiali. Paremaks vahendiks on tänapäeval astronoomilistel vaatlustel kasutatav tahke keha vastuvõtja CCD, mis on korraga nii tundlik kui ka kiire, st võimaldab saada pilte ka lühikeste selgusehetkete jooksul. Kõige parem on muidugi teha vaatlusi Maa atmosfäärist väljaspool, nagu Hubble'i-nimeline teleskoop või saata automaatjaam planeedi juurde.
Ta polnud siiski esimene, kes nimetust canali Marsi puhul kasutas. Varem oli seda teinud itaalia astronoom Secchi ühe teistsuguse pinnamoodustise kohta. Schiaparelli mõistes kanaleid olid mõned astronoomid varemgi tähele pannud, nende seas ka Tartu Tähetorni direktor J. H. Mädler. Nad olid märganud vaid mõnda üksikut kanalit, see-eest Schiaparelli kandis oma Marsi kaardile neist terve võrgustiku. See ei tähenda, et ta oleks neid kõiki korraga näinud: kanalid ilmutasid end temalegi ühe- või kahekaupa, seejuures mitte alati siis, kui Marss kõige lähemal oli, vaid sageli palju hiljem.

Flammarioni poolt vaadeldud Marsi kanalid.

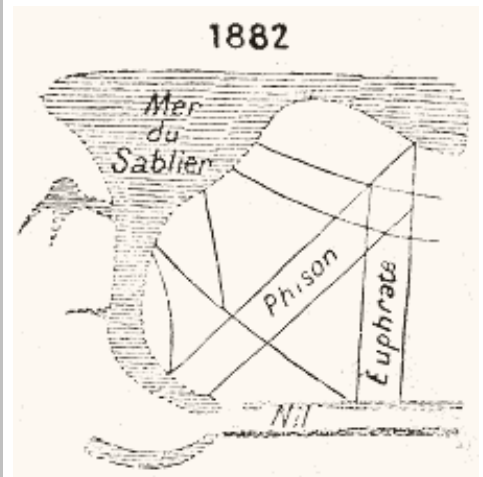

Loomulikult ei jäänud Schiaparelli ka viimaseks, kes kanaleid nägi. Järgmiste vastasseisude ajal nägid neid juba mitmed astronoomid, nagu näiteks N. Green 1879. aastal H. Perrotin 1886. aastal ja kuulus prantsuse astronoom Camille Flammarion (1842-1925) 1892. aastal. Kõige edukam kanalite uurija ja populariseerija oli aga kahtlematult ameeriklane Percival Lowell (1855 - 1916). Sellel edukal äri- ja kirjamehel, kes oli aastaid elanud Jaapanis, tekkis astronoomia ja eriti Marsi huvi 1890ndate alguses. 1894. aastal rajas ta Flagstaffi Arizona osariigis observatooriumi, mille peamiseks tööks pidi kujunema Marsi ja teiste planeetide vaatlemine. Tulemused ei lasknud end kaua oodata. Juba oma esimese, sellel samal aastal toimunud Marsi vastasseisu järel jõudis ta järeldusele, et kanalid on mõistuslike olendite kätetöö, eesmärgiks niisutada "oaase". "Oaasideks" kutsus ta laike kanalite ühinemispunktides, mida tema kaaslane William Pickering (1858 - 1938) oli 1892. aastal nimetanud järvedeks. 1895. aasta veebruaris pidas ta oma vaadete tutvustamiseks seeria avalikke loenguid, sama aasta detsembris ilmus tema esimene Marsi-teemaline raamat lühikese pealkirjaga "Marss".

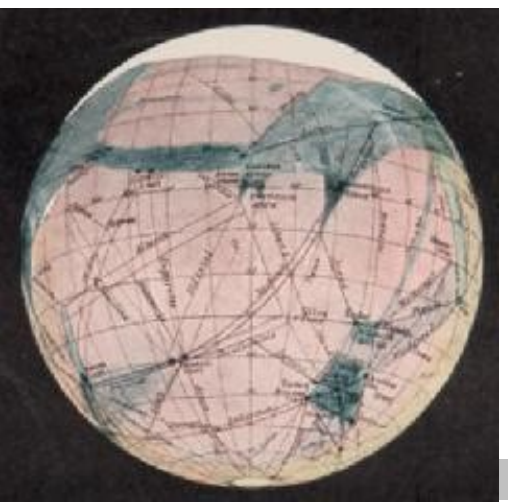


"Tavaliste" inimeste hulgas omandasid P. Lowell ja tema ideed suure populaarsuse, astronoomide seas aga leidus hulgaliselt kahtlejaid. Mitmed tuntud astronoomid, nende hulgas ka väga heade vaatlejatena tuntud A. Hall ja Edward Emerson Barnard (1857 - 1923) ei näinud kanaleid üldse. Seejuures olid neil kasutada märksa suuremad teleskoobid kui Lowellil. Juba 1882. aastal, tükk aega enne P. Lowelli astronoomiaalase tegevuse algust oli inglise astronoom Edward Walter Maunder (1851 - 1928) avaldanud arvamust, et Schiaparelli on oma kanalid tõmmanud erineva heledusega alade piiridele. Hiljem tegi ta katseid valgele paberile tehtud tumedate täppidega ja leidis, et ühes reas olevad silma eraldusteravusest väiksemad punktid paistavad sirgjoonena. Tema arust saaks nii ka Marsi kanaleid seletada. Seda arvamust toetasid ka itaalia astronoomi Vincenzo Cerulli 1897. aastal tehtud vaatlused, mille käigus kanalid paistsid koosnevat täppidest.

See kõik Percival Lowelli ei häirinud. 1896. aastal jõudis ta koguni niikaugele, et väitis ka Veenusel asuvat kanalite taolisi moodustisi! See "avastus" leidis eriti külma vastuvõtu, sest Veenus teati olevat kaetud tiheda pilvkattega. Vahemärkusena võib öelda, et kuigi kanalitega $P$. Lowellil ei vedanud, oli tal tähtis osa uue planeedi otsingute alustamisel. See viis Pluuto avastamisele 1930. aastal Clyde Tombaugh poolt sellesamas, nüüd juba Lowelli nime kandvas observatooriumis.

Kanalite probleemi lahendamisel oli väga oluline kreeka päritolu prantsuse astronoomi Eugene Michael Antoniadi (1870 - 1944) tegevus, kellest kujunes üks 20. sajandi esimese poole parimatest Marsi vaatlejatest. Alustanud 1893. aastal Flammarioni assistendina, oli ta algul veendunud kanalite objektiivses eksistensis. Aja jooksul tekkisid tal siiski kahtlused ja juba 1903. aastal koostas ta lisaks tavapärasele, kanalitega kaetud Marsi kaardile veel teise, millel polnud kanaleid kujutatud. Lõplikult ütles ta kanalitest lahti 1909. aastal Marsi suure vastasseisu järel.

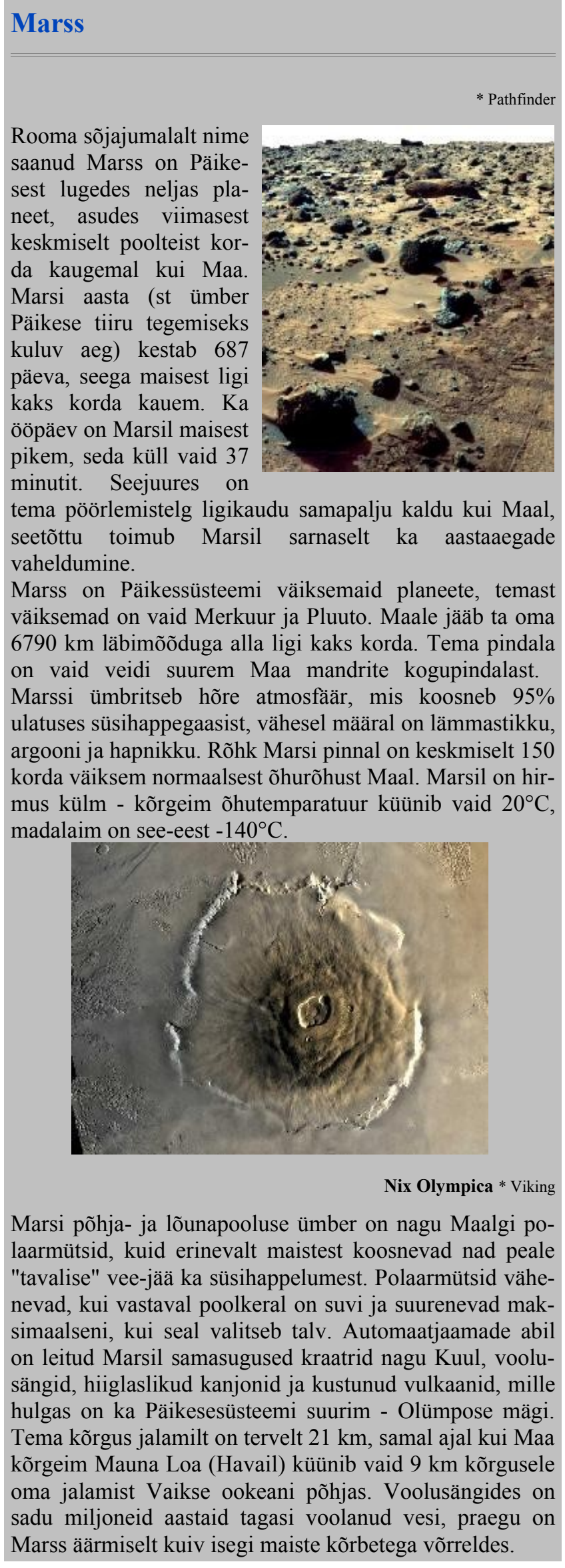



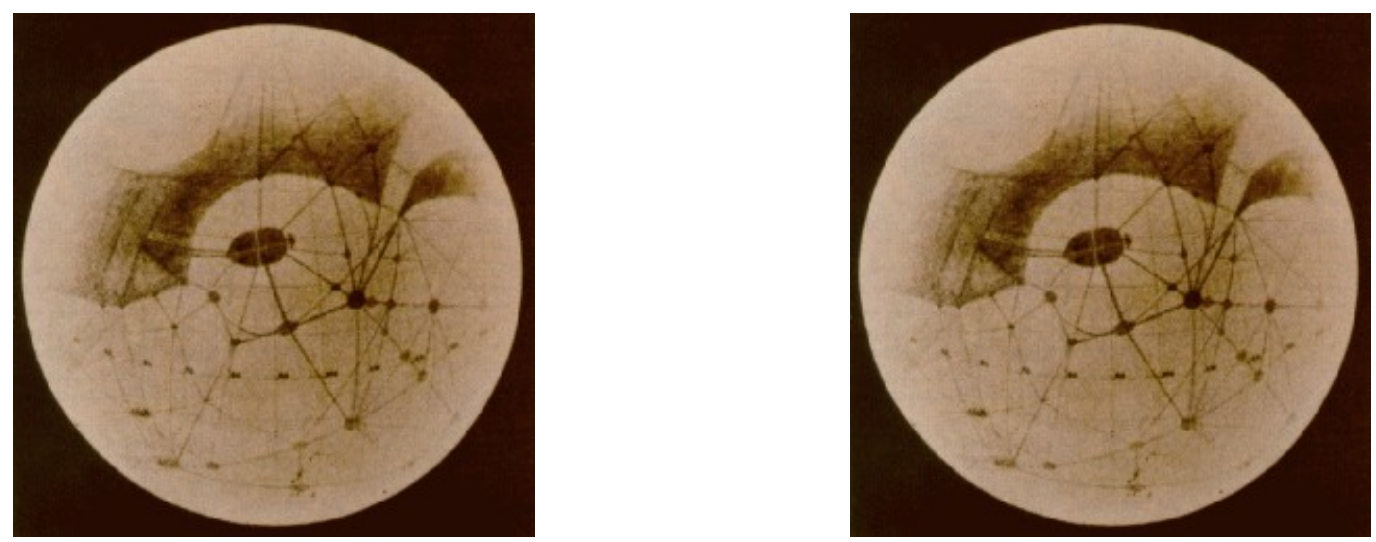

P. Lowelli poolt 1894 a. tehtud joonis Marsist, millel on kujutatud kanalid.

Kui kogu Marsi pinnal ja atmosfääris olev vesi kataks terve planeedi ühtlase kihina, oleks selle paksus vaid 0,014 mm, maistes kõrbetes oleks sellise kihi paksus tervelt $1 \mathrm{~mm}$.

Maalt teleskoobiga vaadates on sellest kõigest näha vaid punakas ketas ja polaarmütsid, suurema teleskoobi ja hea nähtavuse korral paistavad ka mõningad tumedamad ja heledamad laigud. Need ei vasta täpselt mingile Marsi pinnavormile, vaid kujutavad endast erineva peegeldumisvõimega (albeedoga) alasid, näiteks tihedalt kraatritega kaetud alad paistavad olevat tumedamad.

Marsil on ka kaks imepisikest ebakorrapärase kujuga kaaslast, mis kannavad sõjajumala saatjatele hästisobivaid nimesid Phobos (kr. k. hirm) ja Deimos (kr. k. õudus).

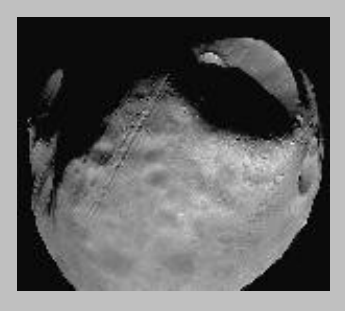

Phobos

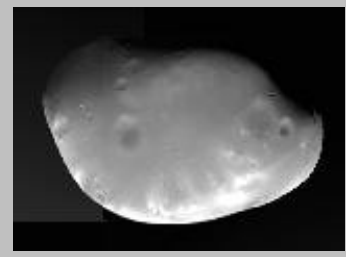

Deimos
E. M. Antoniadi poolt 1909 a.
alast. Tema kanaleid ei näinud.

Siis andis Meudeni observatooriumi direktor talle võimaluse vaadelda Marssi suure refraktoriga (läätsteleskoobiga), mis oma $83 \mathrm{~cm}$ läbimõõduga objektiiviga oli (ja on praegugi) suurim Euroopas ja kolmas kogu maailmas. Esimesed vaatlusööd olid harukordselt hea nähtavusega. Sellele vaatamata ta mitte midagi kunstlikku ega geomeetrilist ei näinud, suurepäraselt nähtav Marss oli kaetud vaid vöötide ja laikudega. Nähtu tulemusena jõudis Antoniadi pöördelise tähtsusega järelduseni, et pole kunagi ühtki tõelist Marsi kanalit nähtud. Tegemist on vaid illusiooniga, mis tekib silma ülepingutamisel soovist näha võbeleval kujutisel harvade selgushetkete jooksul võimalikult peeneid detaile. Lisaks tehti selle sajandi esimesel poolel spektroskoopiliste ja teiste astrofüüsikaliste meetoditega selgeks, et Marsi atmosfäär on väga hõre, seal on vähe veeauru ja valitseb kõva pakane, mis muudab elu võimalikkuse enam kui kaheldavaks.

Sellele vaatamata ei surnud usk mõistusliku elu ja kanalite olemasollu Marsil koos P. Lowelliga 1916. aastal. Nii kirjutas veel 1962. aastal oma raamatus (õigemini fotoalbumis) "Fotograafiline jutustus Marsist" Lowelli kaastöötajana alustanud Earl C. Slipher: "On veel üks liik moodustisi, mis kulgevad läbi Merede ja kõrbete, mässides peaaegu terve planeedi oma võrku - see on unikaalne Marsi kanalite süsteem. Sellele imelisele Marsi võrgule ei ole paarilist ühelgi teisel planeedil ja ta pole võrreldav mitte millegagi looduses. Oma kunstliku olemuse tõttu on nad muutunud kõige müstilisemateks ja kummatigi kõige vaieldavamateks planetaarseteks moodustisteks." (E. C. Slipher tegi ajavahemikul 1905 kuni 1964 Marsist 100000 fotod, mille paremik ongi selles raamatus esindatud.) Ka eesti astronoomi Ülo-Ilmar Veltmanni 1968. aastal ilmunud raamatus "Marss" 
räägitakse kanalitest kui tõsiasjast ja refereeritakse mitmeid hüpoteese nende olemuse seletamiseks. See on seda imelikum, et vahepeal, 1964 aastal lendas Marsist mööda USA automaatjaam "Mariner 4" ning edastas 22 fotot, millel oleks pidanud olema vähemalt üks kanal. Kanaleid aga fotodel ei olnud, selle asemel oli seal näha hulgaliselt kraatreid nagu Kuul. See oli täielik üllatus kõigile peale mõne üksiku astronoomi, kes olid kraatrite olemasolu juba varem ette näinud. Nende väheste hulgas olid ka eesti soost Ernst Öpik ja Pluuto avastaja Clyde Tombaugh.

Sellega jõudis Marsi kanalite lugu lõpule, lugu, mis oli inimeste tähelepanu köitnud juba ligemale sajandi.

\section{Kirjandus}

Lowell, P. 1895. Mars.

URL: http://www.bibliomania.com/NonFiction/Lowell/Mars

Sheehan, W. 1996. The Planet Mars: A History of Observation and Discovery. University of Arizona Press.

URL:http://www.uapress.arizona.edu/online.bks/mars/contents.htm

Slipher, E. C. 1962. The Photographic Story of Mars. Sky Publishing Corporation, Northland Press. Veltmann, Ü.-I. 1968. Marss. Kirjastus "Valgus".

\section{Marss ja Science Fiction (SF)}

Marss kui veel hiljaaegu levinud arvamuse järgi asustatud planeet on köitnud ka SF-kirjanike tähelepanu.

Üks vanemaid ja kuulsamaid Marsiga seotud SF teoseid on inglise kirjaniku Herbert Wellsi "Maailmade sõda" (1897), mis käsitleb marslaste sissetungi Maale. Eriti tuntuks sai see Orson Wellesi juhtimisel 30. oktoobril 1938 USA-s esitatud raadiointseneeringu järel, mida paljud võtsid tegelikkuse pähe. Seevastu nõukogude vene kirjaniku Aleksei Tolstoi romaan "Aeliita" (1922) käsitleb revolutsiooni tegemist Marsil kahe venelase juhtimisel. Terve seeria Marsiteemalisi raamatuid on kirjutanud aastatel 1911 - 1941 Edgar Rice Burrough, kes on rohkem tuntud oma Tarzani-lugudega.

Pärast Teist maailmasõda kirjutatud suurest hulgast vastavatest raamatutest tõuseb esile Ray Bradbury "Marsi kroonikad" (1951). Teistes kuulsatest SF autoritest on Marsi teemat käsitlenud veel Isaac Asimov ("David Starr, Space Ranger", 1952), Robert Heinlein ("Red Planet ", 1949), Arthur C. Clarke ("The Sands of Mars", 1951) jt. Viimase kümnendi töödest on suuremat tähelepanu äratanud Kim Stanley Robinsoni triloogia "Red Mars" (1992), "Green Mars" (1993) ja "Blue Mars" (1996).

Linkide õigsuse eest pikema aja jooksul autor ja toimetus ei vastuta. Marsi kohta leiad infot ka Tartu Tähetorni WWW-lehelt. 